\title{
Increasing attitudes and interest in caring for older adults in first year nursing students using innovative teaching and learning strategies
}

\author{
Karen Parsons *1, Sandra MacDonald ${ }^{1}$, Allyson Hajek ${ }^{2}$, Judy Moody ${ }^{1}$ \\ ${ }^{1}$ School of Nursing, Memorial University, St. John's, Newfoundland and Labrador, Canada \\ ${ }^{2}$ Distance Education, Learning and Teaching Support, Memorial University, St. John's, Newfoundland and Labrador, Canada
}

Received: March 29, 2015

DOI: $10.5430 /$ jnep.v5n9p63
Accepted: May 25, 2015

Online Published: June 18, 2015

URL: http://dx.doi.org/10.5430/jnep.v5n9p63

\begin{abstract}
Objective: The purpose of this study was to determine if the course Healthy Aging had any impact on nursing students' attitudes towards older adults and/or interest in their caring for older adults after the completion of nursing school.

Methods: A pretest-posttest design was used. A convenient sample of 54 first year baccalaureate nursing students enrolled in the course Healthy Aging at Memorial University School of Nursing, St. John's, Newfoundland, Canada was recruited for in the study. On the first day of class 51 students consented to participate in the study. During the second and last classes of the course the Kogan's (1961) Attitudes Towards Old People Scale (KOP) was administered to compare student attitudes towards older adults before and after completion of the course. Students were also asked pre and post course whether they would consider working with older adults after the completion of nursing school. Students' perceptions of the innovative teaching strategies used in course delivery and how they contribute to knowledge, attitudes, and interest regarding older adults were also evaluated. Descriptive statistics were used to summarize demographic information and obtain means and standard deviations on the KOP. Results: Thirty-three students completed both the pre and post-tests. KOP scores were fairly high at both the beginning and at the end of the course. The students in the first year of nursing studies entered the course with a fairly positive attitude toward older adults. Of the 33 students, 19 students $(57.5 \%)$ stated they would definitely consider working with older adults and 8 students (24.2\%) stated that they might consider working with older adults, at the completion of nursing school. Only 2 students stated they would definitely not consider working with older adults after completion of nursing school. This was somewhat surprising in light of previous research in this area. Although there was no significant increase in KOP scores at the completion of the course, $27(81.5 \%)$ students said that they would definitely work with older adults at the completion of nursing school. Qualitative data revealed that students had a greater interest in working with older adults at the end of the course than they did prior to taking the course. Results revealed that educational strategies were highly influential in this positive change of interest and provided evidence of the importance of making the content contextually relevant and interesting. Furthermore, a positive attitude by faculty and enthusiasm toward the older adult and toward gerontological nursing is equally important in providing a positive influence on students' perceptions.

Conclusions: Participating in the Healthy Aging course increased students' attitudes and interest in caring for older adults.
\end{abstract}

Key Words: Nursing students, Attitudes, Interest, Older adults Canada.

*Correspondence: Karen Parsons; Email: karenp@mun.ca; Address: School of Nursing, Memorial University, 300 Prince Philip Drive, St. John’s, 


\section{INTRODUCTION}

The world population is aging rapidly and the number of older adults in developing countries who will not be able to care for themselves is forecast to quadruple by $2050 .{ }^{[1]}$ Furthermore, the nursing workforce is also aging and the number of nurses is projected to be inadequate to fulfill the needs of this aging population. The corresponding increase in incidence and prevalence of chronic illness in older adults and the current shortage of registered nurses specializing in gerontological nursing have placed a strain on current nursing resources. ${ }^{[2]}$ This worldwide demographic trend of an aging population is anticipated worsen between 2020 and 2040 , when many of the baby boomers enter the oldest age groups and require the most care. ${ }^{[3]}$ Therefore, there is an urgent need to create an interest in gerontological nursing and to prepare new graduates to work with this population.

Young, newly graduated nurses do not generally select gerontological nursing as their first career choice. ${ }^{[4]}$ One reason for this shortage of registered nurses pursuing a career in gerontology is that undergraduate nursing students often have a negative view of aging and older adults ${ }^{[5]}$ and many newly graduated nurses often have the perception that gerontological nursing is uninteresting, requiring less technical skill, and having a heavier physical workload than other nursing specialties. ${ }^{[4]}$ Negative attitudes toward aging are known to decrease the quality of care for older adults. ${ }^{[6]}$ The root of this perception may be that historically the inclusion of gerontological nursing content in university baccalaureate programs has been sparse. ${ }^{[7-9]}$ The inclusion of gerontological nursing content in nursing curricula was determined to be slow due to lack of faculty expertise and interest, student preference, and competing interests such as surgical nursing. ${ }^{[10]}$ The Canadian Gerontological Nursing Association (CGNA) ${ }^{[11]}$ and the National Gerontological Nursing Association (NGNA) ${ }^{[12]}$ have identified and addressed this issue by creating objectives to promote high standards of gerontological nursing practice in Canada and the United States.

Many schools of nursing in Canada and the United States responded to the challenge of a need for gerontological nurses by introducing gerontological courses into their baccalaureate curriculums. Despite this, having gerontology in the curriculum may not in itself be enough to create an interest in gerontological nursing and prepare nurses to work with this population. To deliver high-quality care to older patients nurses need to receive adequate preparation in gerontological nursing. In a study to determine the status of gerontology in Canadian nursing programs, Baumbusch and Andrusyszyn ${ }^{[13]}$ determined that the content of gerontology in Canadian nursing programs has much potential for devel- opment. They determined that there is a need for faculty expertise, a need to address ageism and a need for much more innovative forms of course delivery other than common didactic teaching. In 2009 the editor of the Canadian Journal of Nursing Research wrote an editorial voicing his concern that education in gerontology was often not a priority in Canadian Universities. ${ }^{[14]}$ In September 2010, during an address to the School of Nursing, University of Maryland, Patricia Benner presented findings and recommendations from the National Nursing Education Study, the first of its kind in more than 30 years. She said "the classroom is in really bad shape" and that the study recommends what she called "a major shift in nursing education from abstract classroom teaching to teaching from a sense of salience." According to Benner, by focusing on the relevancy of the content and contextualizing it, "students are absolutely engaged because they know they are rehearsing for their practice." Thus in an effort to address this need for relevant and contextualized gerontological content in nursing education, the Healthy Aging course was created at Memorial University of Newfoundland, School of Nursing for first year nursing students.

\subsection{Purpose and objectives}

The purpose of this study was to determine if the course Healthy Aging had any impact on nursing students' attitudes towards older adults and/or interest in their caring for older adults after the completion of nursing school.

Specific objectives of the study were:

(1) To determine if the course Healthy Aging resulted in a change in nursing students' attitudes toward older adults.

(2) To determine if the course Healthy Aging resulted in a change in students' interest toward working with older adults upon completion of nursing school.

(3) To determine students' perceptions of the impact of the teaching strategies used in course delivery on their knowledge, attitude and interest toward older adults (e.g., online case studies with discussion, a selfdiscovery tapestry assignment, assessment of a well older community dwelling adult, the sharing of stories by the course professor, classroom-based activities).

\subsection{Theoretical framework}

The theoretical frameworks of Rokeach's (1968) Theory of Organization and Change ${ }^{[15]}$ and the Theory of Transformative Learning ${ }^{[16]}$ guided this study. According to Rokeach, attitudes influence behavior. Attitudes are clusters of beliefs that lead to behavioral response. Values as defined by Rokeach, are core conceptions of the desire within every individual and society. Values serve as standards to guide action, 
judgment, choice, attitude, evaluation, argument, rationalization, and attributions of causality. A person's attitude can be influenced by thing such as social milieu, direct experience and cognitive learning. ${ }^{[17]}$ It is reasonable to assume that direct experience and theoretical content in nursing schools can lead to transformative attitude change. Transformative learning is when habitual thinking processes and assumptions are transformed such that they become "more inclusive, discriminating, open, reflective, and emotionally able to change". [16] The course Healthy Aging has been developed as the name suggests, to help students conceptualize the aging process and the older adult in a positive way, and to encourage a proactive role for nursing in the promotion of healthy aging. The literature supports such an approach for the potential to enhance student appreciation of aging issues. ${ }^{[18,19]}$

\subsection{Couse description}

The first year of the Baccalaureate Nursing Program at Memorial University of Newfoundland includes both a theoretical course and a clinical course that focuses on caring for the older adult. Healthy Aging is a theoretical course that is designed to prepare students with the basic knowledge and concepts necessary for meeting the needs of the well elderly client $(65+$ years). Emphasis is placed on well older adults living in the community as opposed to long-term care. The content provides a foundation for further nursing courses in the program including a clinical course in gerontological nursing that involves nursing practice in a long-term care facility. Although some nursing programs emphasize fundamental nursing skills in gerontology nursing courses, the focus of the Healthy Aging course is to study aging of the older adult from a biological, psychological, social, spiritual, and cultural perspective, with an emphasis on the impact of the determinants of health on healthy aging and promotion of health and safety. Emphasis is also placed on the role of the nurse in health promotion, disease and illness prevention, and health maintenance for the older adult.

\subsection{Educational strategies}

Several educational strategies were used for course delivery by the course professor who was also the primary researcher for this study: case studies with online case studies with discussion, assessment of a well older adult living in the community, self-discovery tapestry, and sharing of stories and classroom-based activities.

\subsubsection{On-line case studies with discussion}

Each course topic was followed by an online case study assignment in which student groups discussed the case and answered questions via the Desire to Learn (D2L) system. D2L is Memorial University's Learning Management System that provides a secure location for content, assessment, and communication. Access is password protected and only those students and faculty affiliated with the course or support staff have access to the content. Each case study included a scenario that was deemed challenging to the student in providing care for the older adult. The discussion questions were intended to increase students' understanding of the topic by challenging them to read related literature on the topic, think more deeply and to critically analyze each scenario.

\subsubsection{Assessment of a well older adult living in the com- munity}

Each student selected a well older adult (65+ years) living in the community for the assessment. The older adult was someone who was personally known to the student such as a relative or neighbour who gave consent to be visited and interviewed. Each student prepared a list of objectives for the visit to the older adult's home. Each student performed the following assessments: environmental assessment, nutritional assessment, medication review, pain assessment, spiritual assessment, assessment of activities of daily living and instrumental activities of daily living, assessment of rest and sleep patterns, and assessment of transitions. Following the visit students wrote a short paper that summarized the older adult's health status and discussed the potential role of the nurse in regards to health promotion and disease and illness prevention.

\subsubsection{Self-discovery tapestry}

In conjunction with the assessment assignment discussed above each student was required to develop a tapestry of the life histories of their selected client. Adapted from the Self-Discovery Tapestry developed by Meltzer, Abbott, and Spradling ${ }^{[20]}$ the tapestry provided a learning opportunity to discover similarities in their own lives with that of the older adult. To create self-awareness, students were first also asked to create a tapestry of their own lives. Tapestries included major life events in one column, perception of the life event in another column, awareness of how life events affected significant others in the third column and the personal meaning of each life event in the final column. Each student was also asked to reflect upon the tapestries and consider similarities between themselves and the older adult. The students were then asked to reflect upon what they believed the assignment contributed to their understanding of the older adult and attitudes toward caring for this population. This assignment was intended to enable the student to see beyond the age and or disability of the older adult and view the older adult as a unique individual. 


\subsubsection{Sharing of stories and classroom-based activities}

One of the most effective modes to transfer information is story telling. Stories capture interest and attention, enable recall of details by association, and bring facts to life by putting them in personal scenarios. ${ }^{[21]}$ Stories demonstrate values and therefore may have great influence on learning. ${ }^{[22]}$ The stories shared with the students during the class were of the course professor's own personal experiences in caring for older adults. These were stories that were deemed meaningful and contextually relevant to the course topic.

Classroom-based activities were also carried out as a means of targeting attitudinal change in students through experiential learning. ${ }^{[23,24]}$ Examples of the classroom-based activities are: asking students to refrain from repositioning themselves in their chairs during the class on age-related integument changes and skin breakdown so that they would experience how feels to be left too long without turning and repositioning, and student role playing on proper communication between the nurse and the older client with impaired hearing or visual impairment.

\section{METHODS}

A pretest-posttest design was used to determine if the course Healthy Aging had an impact on nursing students' attitudes toward older adults and/or interest in caring for older adults after the completion of nursing school.

\subsection{Sample}

A convenient sample of first year baccalaureate nursing students $(\mathrm{N}=51)$ enrolled in the course Healthy Aging at Memorial University of Newfoundland School of Nursing, of which 49 females and 2 were males, took part in the study. Fiftyone students completed the questionnaires on the first day of class (T1) and 36 students participated on the last day of class (T2). Thirty-three students completed the questionnaires at both $\mathrm{T} 1$ and $\mathrm{T} 2$. The other characteristics of the students are described in Table 1.

Approval to conduct the study was obtained from Memorial University of Newfoundland's Health Research Ethics Authority and the School of Nursing Executive Committee.

\subsection{Instruments}

Demographic information including age, previous courses taken in university or elsewhere about the older adult, and any previous experience working with older adults was obtained. Students were also asked to specify if any of the previous courses were nursing related, and to briefly describe any previous work experience.

66
Table 1. Demographic characteristics of $1^{\text {st }}$ Year student enrolled in healthy aging

\begin{tabular}{lll}
\hline Items & $\mathbf{N}=\mathbf{5 1}$ & $\mathbf{N}=\mathbf{3 3}$ \\
\hline Age & & \\
Mean & 21.1 & 20.79 \\
Std. Deviation & 3.431 & 3.822 \\
Range & $18-32$ & $18-32$ \\
Previous courses about older adults & & \\
No & 48 & 32 \\
Yes & 3 & 1 \\
Previous experience with older adults & & \\
No & 17 & 12 \\
Yes & & \\
$\quad$ Personal & 13 & 9 \\
$\quad$ Volunteer & 8 & 7 \\
$\quad$ Paid & 3 & 1 \\
$\quad$ Personal + volunteer & 3 & 2 \\
$\quad$ Personal + paid & 1 & 1 \\
$\quad$ Volunteer + paid & 1 & 0 \\
$\quad$ Educational (high school co-op, LPN) & 1 & 1 \\
Educational + personal & 1 & 0 \\
$\quad$ Educational + paid & 1 & 0 \\
Missing data & 2 & \\
\hline
\end{tabular}

Kogan's (1961) Attitudes Towards Old People Scale $(\mathrm{KOP})^{[25]}$ was used to determine student attitudes towards older adults. The KOP is a 34-item Likert-type instrument consisting of 17 matched positive and negative item pairs of attitudinal statements about the elderly. Participants agreed or disagreed with the items using six-point descriptors ranging from (1) strongly disagree to (6) strongly agree. Missing data on SPSS was replaced with the midpoint number 3.5, a strategy supported by Palliant. ${ }^{[26]}$ To obtain a single score for all items, the value of the negative items was reversed and averaged with the positive responses. Thus higher scores indicated a more positive attitude toward the elderly and lower scores indicated a more negative attitude toward the elderly. Therefore scores on the KOP can range from 34 to 204. Kogan reported a Cronbach's alpha of 0.66 to 0.83 for individual subscales for his sample of 178 respondents. Permission to use the instrument was obtained prior to its use.

At T1 and T2 students were asked the question: Would you consider working with older adults upon completion of nursing school, why or why not? At T2 students were also asked the question: Tell me your perceptions of the following course activities and how they contribute to your knowledge, attitudes, and interest regarding older adults: online case studies with discussion, assessment of a well older adult living in the community, self-discovery tapestry, and the sharing of stories and classroom-based activities. 


\subsection{Recruitment and data collection}

On the first day of class, 54 students enrolled in the course Healthy Aging, were recruited for the study. As the course professor was also the primary investigator of the study consent to participate in the study was obtained by a paid research assistant. To avoid any feelings of coercion on the part of the participants, the primary investigator was not in the room during the information and consent process or the actual filling out of the questionnaires. After the research assistant explained the purpose of the study and an opportunity was provided to ask questions students were given the choice of whether or not to participate. Completion and submission of the questionnaires was deemed as acknowledgement that participants understood the study, expectations of their participation and associated rights. Students were asked to attach a personal identifier on the questionnaires that only they would know. It was made clear to the participants that an identifier was required only to facilitate matching of data from $\mathrm{T} 1$ to $\mathrm{T} 2$ and that only aggregated data would be communicated or published. Students completed the demographic data sheet at $\mathrm{T} 1$. The KOP and qualitative questions were completed at both $\mathrm{T} 1$ and $\mathrm{T} 2$. The research assistant collected the questionnaires and separated the demographic information sheets from the surveys prior to data entry. The qualitative data were typed, verbatim, by the research assistant to ensure anonymity of responses.

\subsection{Data analysis}

Descriptive statistics were used to summarize demographic information and obtain means and standard deviations at $\mathrm{T} 1$ and $\mathrm{T} 2$ on the KOP for the 33 matched T1 and T2 scores. Statistical analysis was done using SPSS version 21. A paired samples $t$-test was used to determine if the course Healthy Aging resulted in a change in nursing students' attitudes toward older adults between T1 and T2. At T1 a paired sample t-test was also used to determine if there was a difference between students who had no previous experience with older adults and those who had previous experience (formal and personal) with older adults and their attitudes on the KOP.

Qualitative data were categorized. Students who indicated that they were definitely considering working with older adults were categorized as "definite yes". Students who stated that they were uncertain if they would like to work with older adult and gave a qualified yes, meaning for example, that it depended upon what was available, or if they had no preference, or were undecided, were categorized together at T2 as "uncertain". Students who stated they had no interest in working with older adults were characterized as "definite no".

Published by Sciedu Press

\section{RESULTS}

At T1 KOP scores were separated between positive and negative sub-scales. The 33 participants at $\mathrm{T} 1$ scored a mean of 74 (range of 49-78; SD = 6.2) on the positive items and a mean of 79 (range of 36-89; SD = 10.9) on the negative items. For both the positive and negative items, a higher score indicates greater positive attitudes. At $\mathrm{T} 2$ the $33 \mathrm{stu}-$ dents had a mean score on the positive items of 77 (range of 63-81; SD = 8.8) and on the negative items 78 (range of 63-94; SD = 9.4). Descriptive statistics were available for the whole cohort of students $(\mathrm{N}=51)$ only at $\mathrm{T} 1$. At $\mathrm{T} 1$, the cohort scored a mean of 75 (range of 56-93; SD = 7.66) on the positive items of the KOP. On the negative KOP items the students scored a mean of 76 (range of 38-96; SD $=10.99$ ). The results indicate that the cohort of students had reasonably positive attitudes towards the elderly at T1. 33 students repeated the KOP at T2, however, there was only a slight increase in attitude over the course of the program. There was no significant difference between KOP scores at T1 for students who had no previous experience with older adults and those who had previous experience (formal and personal) with older adults (overall KOP scores of 152 and 153 respectively).

Table 2 summarizes the change in students' interest in working with older adults upon completion of nursing school from $\mathrm{T} 1$ to $\mathrm{T} 2$.

At T2, 27 students $(81.8 \%)$ indicated that they would definitely consider working with older adults upon completion of nursing school as compared 19 students $(57.6 \%)$ at $\mathrm{T} 1$. One student went from "definite yes" to "uncertain", while another went from "definite no" to "definite yes." Overall, 9 students (27.3\%) who were either "uncertain" or "definite no" at $\mathrm{T} 1$ changed to definitely wanting to working with older adults at T2. Examples of written positive responses from the 8 students who went from "uncertain" or "definite no" to a "definite yes" are summarized in Table 3 .

There were 25 positive responses indicating students found the e-learning case studies to be interesting and helpful in applying theory to practice and increasing their knowledge and interest in caring for older adults. There was 1 negative response and 7 unanswered responses on this aspect of the questionnaire. Following are examples of the positive comments:

I found the case studies interesting. They helped use critical thinking and helped me to understand the material.

These helped me a lot. We got a chance to be given scenarios and actually think about what we would do. It made me aware of any biases that I may have and helped me fix them. 
Table 2. Would you consider working with older adults upon completion of nursing school? $(\mathrm{N}=33)$

\begin{tabular}{lllll}
\hline & T1 & T2 & Change from T1 to T2 & \\
\hline Definite yes & $19(57.5 \%)$ & $27(81.5 \%)$ & Definite yes to definite yes & $18(54.5 \%)$ \\
Qualified yes (i.e., depends) & $8(24.2 \%)$ & $5(15.5 \%)$ & Definite yes to uncertain & $1(3 \%)$ \\
No preference & $2(6.1 \%)$ & 0 & Uncertain to definite yes & $8(24.2 \%)$ \\
Undecided & $2(6.1 \%)$ & 0 & Uncertain to uncertain & $4(12.1 \%)$ \\
Definite no & $2(6.1 \%)$ & $1(3 \%)$ & Definite no to definite yes & $1(3 \%)$ \\
& & & Definite no to definite no & $1(3 \%)$ \\
\hline
\end{tabular}

Table 3. Examples of change in individual students' responses from T1 to T2 (Consider working)

\begin{tabular}{|ll|}
\hline Uncertain (T1) & Definite Yes (T2) \\
\hline $\begin{array}{l}\text { Even though it may be inevitable that I work with the older } \\
\text { adult, I would like to focus my clinical experience in the field of } \\
\text { pediatrics. }\end{array}$ & $\begin{array}{l}\text { Yes because the older adult has a lot to offer because of their } \\
\text { experiences and knowledge. I look forward to helping older } \\
\text { adults optimize and maintain their health to successfully age. } \\
\text { I would consider it but haven't decided yet. } \\
\text { Maybe. I haven't decided where I want to work yet. }\end{array}$ \\
$\begin{array}{ll}\text { I don't have any preference as to where I work. } \\
\text { Yes, I learned so much from completing my paper. } \\
\text { Yes, it is inevitable. Wherever you work today the nurse will be } \\
\text { caring for older adults in some point in their career. }\end{array}$ \\
\hline $\begin{array}{l}\text { Nofinite No (T1) } \\
\text { completion of nursing school. }\end{array}$ & Definite Yes (T2) \\
\hline
\end{tabular}

It gave us insight into what everyone's thoughts and discussions were. I really enjoyed knowing everyone else's opinions.

The majority of students indicated that the assessment of a well older adult living in the community was a positive learning experience:

This was helpful because I got a chance to assess the older adult and actually hear from them. It was nice to hear things from their point of view and listen to their stories.

Helped me communicate with the older adult and realize how an older adult lives on a daily basis. It's one thing to learn about it and another to actually see it.

However, two students found that doing the assessment made them uncomfortable. One student felt that instructions for the assignment were too vague. Seven students did not respond to the question.

Responses to the self-discovery tapestry were mostly positive. Positive response revealed that students found the tapestry helped them connect with an actual older adult and reveal the older adult's world, contributing to an increase in their understanding and self-awareness:

The tapestry opened my eyes to the varying life experiences that the older adult has faced. It also changed my attitude toward how I would provide care to the older adult.

Made me aware of significant events in an older adults life. Also allowed you to realize older adults are the same as everybody else.

Students found that the stories and small class activities brought life and context to the lecture material. They found the stories interesting and appreciated the real life examples. They also found that stories helped them with recall of class material:

They were very enjoyable to listen to. I am still in shock about the old woman she was telling us about. She put things into perspective for us and made things realistic. I love hearing good stories; it helps me learn and remember content.

These stories peaked my interest in particular topics.

I was able to relate theory to real case scenarios and I was able to have a better understanding of the clinical setting.

\section{Discussion}

This study sought to determine if the course Healthy Aging resulted in a change in nursing students' attitude towards older adults, promoted interest in their caring for older adults after the completion of nursing school, and their perceptions 
of the teaching strategies used in course delivery. The results of this study revealed that students in the first year of nursing studies entered the course with a fairly positive attitude toward older adults. This was somewhat surprising in light of previous research in this area ${ }^{[4,27,28]}$ whereby nursing students were found to generally have negative attitudes toward older adults. In our study, given that students' attitudes were reasonably high at the beginning of the course a small positive change in attitude was unremarkable. However, the inclusion of qualitative data revealed that students had a greater interest in working with older adults at the end of the course than they did prior to taking the course. Other studies have investigated whether positive attitudes are related to or influence student preferences to work with older adults upon graduation. Results from those studies have found that although student attitudes are generally positive, they had no interest in working with older adults upon graduation. ${ }^{[29,30]}$ Given the students' positive responses to the qualitative questions regarding the educational strategies used for course delivery, we feel that similar to the findings of others ${ }^{[31]}$ such educational strategies were highly influential in this positive change of interest and provided evidence of the importance of making the content contextually relevant and interesting. Furthermore, a positive attitude by faculty and enthusiasm toward the older adult and toward gerontological nursing is equally important in providing a positive influence on students' perceptions. ${ }^{[32]}$ These findings indicate that the educational strategies used in the Healthy Aging course were influential in creating a positive change of interest in working with older adults and provided evidence of the importance of making the content contextually relevant and interesting.

The course Healthy Aging focuses on well older adults living in the community and on the positive aspects of aging. Although the findings of this study are encouraging, research has shown that clinical placement experience and mentor support are also very important in influencing students' decisions about whether they would consider working with older adults in the future. ${ }^{[8,33]}$ Quite often clinical placements in the care of older adults takes place in long-term care where older adults are oftentimes very frail or sick, and where students may not be exposed to the positive aspects of aging. Nursing students often are not exposed to well older adults who live independently in the community. Responses on the community assessment of the well older adult and the tapestry assignment revealed that students were positive about interviewing older adults who were well enough to share their stories with the students. Students stated that they enjoyed spending time with the older adult and learned to appreciate the positive aspect of seniors and of aging. Students discussed how the assignment opened their eyes to the older adult. Clinical placements in the care of older adults, therefore, need not only take place in long-term care institutions but also in other clinical venues where older adults live and socialize such as assisted living facilities, personal care homes, community centers, daycare centers, and seniors clubs. Furthermore, quite often in nursing programs, clinical sites are selected and deemed appropriate for first year nursing students based on the belief that they offer a slow paced environment requiring limited clinical skills. Unfortunately this kind of thinking prohibits the variety of learning opportunities in nursing homes and perpetuates the myth that care of nursing home residents requires less expertise in nursing skills, critical thinking and leadership as opposed to the care of hospitalized patients on acute care units. ${ }^{[27]}$ Many nursing homes have evolved from merely providing custodial care to providing a range of nursing and rehabilitative services for residents, requiring nurses to have specialized communication skills, knowledge of nutritional factors, and cognitive decline.

Finally, although students' in this study expressed an overall positive attitude on the KOP and a greater interest in working with older adults indicating that they might choose a career in gerontological nursing after graduating from nursing school, attitude and interest does not guarantee compassion and the provision of quality of care for older adults. The clinical placements students encounter and their interactions with nurses, other professionals, and patients are important in shaping compassionate care skills. Role models can best show nursing students that compassion is a fundamental behaviour in providing quality care by modeling their own commitment to compassionate care. ${ }^{[34]}$ It is essential that universities and health service providers work together to ensure that mentors are effectively prepared, supported and developed.

\section{Conclusion}

Results of this study demonstrated participating in the Healthy Aging course increased students' interest in caring for the older adult. Importantly, this research goes beyond students' attitudes toward gerontological nursing in that it offers new insights into the importance of innovative forms of course delivery other than common didactic teaching in sparking interest in the nursing care of older adults. The shortage of nurses continues, as does the need for nurses to competently care for the older adult. Practical steps such as developing and evaluating innovative teaching and learning approaches to preparing students for gerontological nursing practice, focusing on the positive aspects of aging within the course structure, recognizing gerontology as a specialty area and selecting clinical areas that meet the challenges 
of such care, and recognizing the importance of good role models will further the positive shift in attitude and interest in nursing students before they graduate.

\section{Study limitations}

Limitations of the study include its cross-sectional design and use of a small purposive convenient sample from one class at one university, therefore, results cannot be generalized to all nursing students enrolled in gerontological nursing courses.

\section{ACKNOWLEDGEMENTS}

The authors appreciate the contributions of Dr. Wendy Young, Canada Research Chair in Healthy Aging, Memorial University, School of Nursing, for her assistance with proposal writing and data analysis. This research was supported by the Memorial University, School of Nursing Research Grant.

\section{CONFlicts OF INTEREST Disclosure}

The authors declare that they have no competing interests.

\section{REFERENCES}

[1] World Health Organization. Ageing and life course. Facts about ageing. 2014. Available from: http://www. who.int/ageing/about /facts/en/

[2] Evers C, Ploeg J, Kaasalainen S. Case study of the attitudes and values of nursing students caring for older adults. J Nurs Educ. 2011; 50(97): 404-409. PMid:21534499 http://dx.doi .org/10. 3928 /01484834-20110429-03

[3] Cooper EE. Pieces of the shortage puzzle: aging and shift work. Nurs Econ. 2003; 21(2): 75-79. PMid:12739196

[4] Ryan M, McCauley D. J N Y State Nurses Assoc. 2004; 35(2): 5-9. PMid: 15884479

[5] Koren ME, Hertz J, Munroe D, et al. Assessing students' learning needs and attitudes: Considerations for gerontology curriculum planning. Gerontol Geriatr Educ. 2008; 28 (94): 39-54. PMid:19042220 http://dx.doi.org/10.1080/02701960801963029

[6] Eymard AS, Douglas DH. Ageism among health care providers and interventions to improve their attitudes toward older adults: an integrative review. J Gerontol Nurs. 2012; 38(5): 26-35. PMid:22420518 http://dx.doi.org/10.3928/00989134-20120307-09

[7] Gilje F, Lacey L, Moore C. Gerontology and geriatric issues and trends in U. S. nursing programs: a national survey. J Prof Nurs. 2007; 23(1): 21-29. PMid:17292130 http://dx.doi.org/10.10 $16 / j$.profnurs . 2006.12.001

[8] Deschodt M, Dierckx de Casterle BD, Milisen K. Gerontological care in nursing education programs. JAN. 2010; 66(1): 139148. PMid:19968723 http://dx.doi.org/10.1111/j.1365-2 $648.2009 .05160 . x$

[9] Mantle J. Nursing Care of the Aged in Canada. J Gerontol Nurs 1981; 7: 671-676. http://dx.doi.org/10.3928/0098-9134-1 9811101-07

[10] Beckingham AC, Van Maanen TH, McKnight J. Curriculum innovation for gerontological nursing in Canada: A health for all systems based approach. Int J Nurs Stud. 1992; 29(2): 135-149. http://dx.doi.org/10.1016/0020-7489 (92) 90004-Z

[11] Canadian Gerontological Nursing Association (www.cgna.net)

[12] National Gerontological Nursing Association (www.ngna.org)

[13] Baumbusch JL, Andrusyszyn MA. Gerontological content in Canadian Baccalaureate Nursing Programs: Cause for concern? Can J Nurs Res. 2002; 34(1): 119-129. PMid: 12122768

[14] Rosenberg M. Editorial: The future of training in gerontology in Canada and other random notes. Can J Aging. 2009; 28(2): 93. http://dx.doi.org/10.1017/S0714980809090199
[15] Rokeach M. Beliefs, attitudes and values: A theory of organization and change. San Francisco: Jossey-Bass, 1968.

[16] Mezirow J. Transformative learning as discourse. J Trans Educ. 2003; 1(1): 58-63. http://dx.doi.org/10.1177/154134460325217 2

[17] Rodgers V, Gilmour J. Shaping nurses' attitudes towards older people through learning and experience. Nurs Praxis N Engl. 2011; 27(3): 13-20.

[18] Aud MA. Baccalaureate nursing students' perceptions of the roles of registered nurses in the promotion of healthy aging. J Nurs Care Qua. 2004; 19(4): 305-306. http://dx.doi.org/10.1097/000 01786-200410000-00003

[19] Masters JL, Hooey LM. Encouraging responsible aging through pedagogy: The future self exercise. Gerontol Geriatr. 2009; 30: 34 46. PMid:19214845 http://dx.doi.org/10.1080/027019608 02690266

[20] Meltzer PJ, Abbott P, Spradling P. Teaching gerontology using the self-discovery tapestry: An innovative approach. Gerntol Geriatr Educ. 2002; 23(2): 49-63. http://dx. doi .org/10.1300/J021v 23n02_04

[21] Davidhizer R, Lonser G. Storytelling as a teaching technique. Nurs Educ. 2003; 28: 217-221. http://dx.doi.org/10.1097/00006 223-200309000-00008

[22] Bergman P. Storytelling as a teaching tool. Clin Excell Nurse Pract. 1999; 3: 154-157. PMid:10646409

[23] Buckwater K, Smith M, Martin M. Attitude problems: Aging matters. Nurs Times. 1993; 89: 54-57.

[24] Burbank PM, Dowling CA, Crowther MR, et al. Improving knowledge and attitudes towards older adults through innovative educational strategies. J Prof Nurs. 2006; 22(2): 91-97. PMid:16564473 http://dx.doi.org/10.1016/j.profnurs .2006.01.007

[25] Kogan N. Attitudes toward old people: The development of a scale and an examination of correlates. J Abnorm Soc Psychol. 1961; 62: 44-54. http://dx.doi.org/10.1037/h0048053

[26] Palliant J. SPSS Survival Manual: A Step by Step Guide to Data Analysis using SPSS for Windows, Open University Press; Melbourne, Australia, 3rd edition, 2007.

[27] Aud MAI, Bostick JE, Marek KD, et al. Introducing baccalaureate student nurses to gerontological nursing. J Prof Nurs. 2006; 22(2): 73 8. PMid:16564470 http://dx.doi.org/10.1016/j.profnurs . 2006.01 .005

[28] Soderhamn O, Lindencrona C, Gustavsson, SM. Attitudes toward older people among nursing students and registered nurses in 
Sweden. Nurse Educ Today. 2001; 21: 225-229. PMid:11322814 http://dx.doi.org/10.1054/nedt.2000.0546

[29] Happell B. Nursing home employment for nursing students: Valuable experience or a harsh deterrent? JAN. 2007; 39: 529-536.

[30] Henderson J, Xiao L, Siegloff L, et al. 'Older people have lived their lives': First year nursing students' attitudes towards older people. Contemp Nurse. 2008; 30(1): 32-45. http://dx. doi .org/10.51 $72 /$ conu. 673.30.1.32

[31] Willams B, Anderson MC, Dey R. Undergraduate nursing students' knowledge of and attitudes toward aging: comparison of contextbased learning and a traditional program. J Nurs Educ. 2007; 46(3): 115-120.
[32] McLafferty E, Dinwall L, Halkett A. Using workshops to prepare nursing students for caring for older people in clinical practice. Int J Older People Nurs. 2010; 5: 51-60. PMid:20925757 http://dx.doi.org/10.1111/j.1748-3743.2009.00176.x

[33] Duggan S, Mitchell EA, Moore KD. 'With a bit of tweaking... we could be great'. An exploratory study of the perceptions of students on working with older people in preregistration BSc (Hons) Nursing course. Int J Older People Nurs. 2013; 8(3): 207-215. PMid:22329731 http://dx.doi.org/10.1111/j.1748-3743. 2012.00317. $\mathrm{x}$

[34] Straughair C. Exploring compassion: implications for contemporary nursing. Part 2. BJN. 2012; 12(4): 239-244. PMid:22398938 http://dx.doi.org/10.12968/bjon.2012.21.4.239 